\title{
Late Blight of Potato
}

\author{
Radhika Dhakal Sedhai* \\ Tribhuvan University, Nepal \\ *Corresponding Author: Radhika Dhakal Sedhai, Tribhuvan University, Nepal.
}

Received: September 09, 2019; Published: October 14, 2019

DOI: 10.31080/ASAG.2020.04.0678

\begin{abstract}
Late blight of potato caused by Phytophthora infestans is the severe disease of potato causing the crop failure. It was first reported during the Irish Potato Famine, leading to massive starvation in Ireland and other parts of Europe. The pathogen is sturdy in nature and has various mechanisms of survival. It can affect both the foliage and the tuber through spores. The sexual spore is known as oospore produced by mating of types A1 and A2. The spores can affect healthy plants by finding their ways through rain and wind. Having understood the life cycle of this pathogen, the control would be much easier. There are different strategies for the management of this disease viz: cultural practices, host plant resistance and chemical control. However, an application of single strategy won't be efficient alone. Therefore, combination of these strategies in appropriate time is utmost for the control of late blight in potato. Integrated Disease Management (IDM) has far reaching repercussions than any other management approach.

Keywords: Phytophthora; Irish famine; IDM
\end{abstract}

\section{Introduction}

Late blight of potato caused by Phytophthora infestans is one of the most devastating diseases in potato and tomato. It can occur in eggplant and some other members of the Solanaceae family. During 1840s, people from Ireland suffered starvation due to failure in potato production which was inflicted by Late blight. Before then, people believed it's the decaying of vegetation and wrath of god leading to such famine condition. Later, this famine gave rise to the official initiation of science of phytopathology. Losses from late blight have been calculated to $€ 12$ billion per annum in which developing countries comprise of $€ 10$ billion per annum (Haverkort., et al. 2009). A survey in the United States reported that only for the fungicide application, it costs around $\$ 77.1$ million with an average of $\$ 507$ /ha excluding non-fungicide control practices (Guenthner., et al. 2001).

The disease affects severely in Sub-Saharan Africa (44\% crop losses) followed by Latin America (36\%), Caribbean (36\%), South-
East Asia (35\%), South-West Asia (19\%) and Middle East and North Africa (9\%) [1]. Different researchers have reviewed various aspects of this disease [2].

Symptoms

- $\quad$ Spots formations: At first, small, pale to dark green, irregularly shaped spots with surrounding pale green to yellow rings appear on the leaves. The spots are not bordered by veins but can grow across them.

- Decaying of leaves: In cool, moist weather, the spots grow rapidly into large brown to purplish black areas. The disease may kill entire leaflets or grow down the petioles and into the stem, killing the plant above it. When the weather is moist, a white fungal growth appears on the edges of the dead areas, usually on the undersides of the leaves. In the field, plants often give off a distinctive fetid or decaying odour.

- Primary Tuber infection: On susceptible potato varieties, the tubers can be infected when sporangia are washed off from leaves into the soil. Small to large, slightly de- 
pressed areas of brown to purplish skin can be seen on the outside of the tuber.

- Secondary Tuber infection by bacteria: If potatoes are stored under warm or humid conditions, the rot will continue to progress. Most of the times, soft rot bacteria attack them changing neighbouring healthy potato into a rotten and foul mass which should be thrown away.

Disease cycle and epidemiology

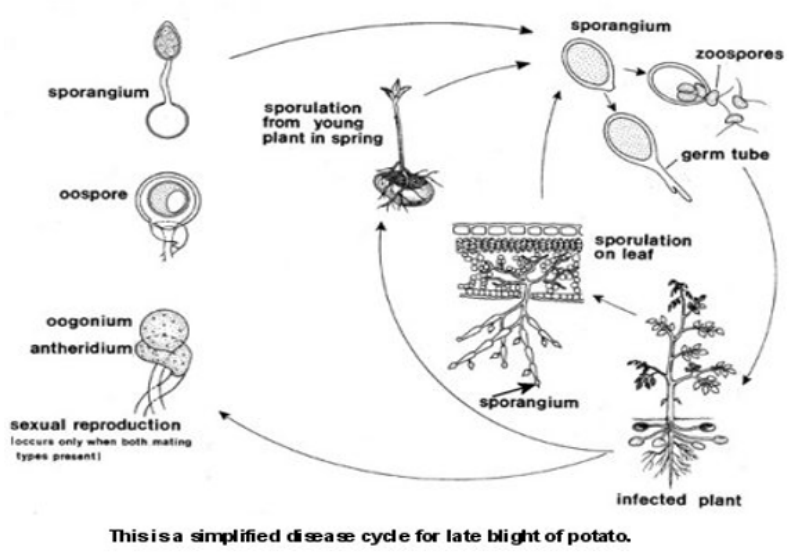

Figure 1: Disease cycle.

In the beginning, potato late blight was supposed to occur because of weather conditions. Later, a fungus, Phytophthora infestans was found to be responsible affecting potato crop under wet conditions. The factors building strong bond between the pathogen and disease include wind velocity, fogginess, $\mathrm{RH}$, light, rainfall, ambient temperature and dew.

\section{Disease cycle}

When the oospore stage is absent, the pathogen survives as mycelium in infected tuber of potato or in tomato fruit. Post-harvest, if infected tubers are left in the fields, the production of sporangia occurs in the next spring from those infected tubers. These sporangia are carried to the next healthy leaf surface by the current of air. Also, infection of seed potatoes can occur sometime and lesions on stem can be seen which can kill the whole plant. During storage, contamination from spores is common in new seed tubers via air. In turn, if these seed tubers are used, local infection is inevitable. Multiplication of pathogen via infected tubers takes place afterwards.
In the presence of water and at cooler temperatures, sporangia germinate indirectly by the production and release of zoospores. At warmer temperatures, the sporangia germinate directly by the production of a germ tube. Several days after infection, new sporangia are produced on sporangiophores, which emerge from stomata. The deciduous sporangia may be dispersed by wind or water to new parts of the same potato plant or new plants. Sporangia may also be washed through the soil to infect tubers. If both mating types come into contact with each other, thick-walled oospores may be produced to persist in soil or plant tissues. In areas where asexual reproduction occurs, oospores usually germinate by producing a sporangium.

\section{Epidemiology}

Development of late blight is favoured by moisture content and temperature. When the RH is less than $90 \%$, Sporangia are produced on the underside of the leaves and infected stems. In hot and dry condition, germination of sporangia takes place via germ tube whereas zoospores are produced in cooler and wet weather condition.

Zoospore is the infective stage of the pathogen that's the reason disease is much more severe in cool and wet condition. The destruction of the whole potato field can be witnessed if the days are warm, nights are cool with prolonged rain and presence of fog. The pathogen sporulates if there is too humid condition in storage. Water droplets are formed as a result of condensation on the infected tuber surfaces causing the sporangia production. These sporangia then infect healthy neighbouring tubers giving the soft rot bacteria chance to act upon and destroy the whole lot.

\section{Sustainable late blight management approaches}

Various management techniques have been discovered and implemented against potato late blight. However, the optimum control can be achieved only through the adoption of integrated approach. The most important measures are cultural, use of resistant cultivars and chemical controls which are explained below:

- Cultural control: The late blight management can be achieved through different cultural practices. The fore and foremost control measure against the late blight is cultural practices (Kirk 2009; Kirk., et al. 2013). Cultural practices are essential in reducing pathogen population by altering its survival, multiplication, spread and penetration. Planting of healthy seed tubers, destruction of 
volunteer potatoes, proper drainage is pivotal in exclusion of late blight (Draper., et al. 1994). Control can be gained through discarding volunteer potatoes and culled piles, adopting good harvesting and post-harvesting techniques and spraying fungicides in relevant time (Davis., et al. 2009). The inoculum sources must be avoided to achieve late blight management. Infected seed tubers, volunteer and cull piles are the primary sources of infection. Therefore, destruction of volunteer and cull potatoes is necessary [3]. Introduction of new strains must be avoided by carefully selecting the seed sources (Kirk 2009). When the upper parts (leaf and stem) are encountered in the field at the time of harvest, it is necessary to destroy them either by mechanical or chemical means so that tubers won't get infected [3].

It is advisable to avoid any situation that enhances late blight development such as over irrigation. Where applicable, orientation of rows should be parallel to the prevailing winds so that the foliage dries faster. Irrigation during mid-day and evening was found to be more effective against infection than that done in morning in Israel (Carlson 1994). Over irrigation and application of fertilizer must be checked during late season. About 15 days prior to harvest, vines must be destroyed. Spraying fungicides on foliage is advantageous after vine destruction as they kill spores living on the leaf (Kirk., et al. 2013). Tuber damage must be avoided during harvest [4]. Dry tubers should be stored whilst maintaining humidity and temperature in storage (Kirk 2009). Tubers from healthy and diseased field must be separately stored. To check growth and spread of pathogen, storage of dried potato in the possible lowest temperature is advisable. Constant observation of potatoes and discarding of diseased tubers in storage is essential to limit spread of the disease (Stone 2009).

\section{Host-plant resistance}

Host plant resistance plays significant role in management of potato late blight as it possesses long-term economic benefits for farmers. It plays important role in reducing the quantity of pathogen $P$. infestans, limiting the chances of fungicide resistance (Hakiza 1999; Mukalazi., et al. 2001). Using varieties that are resistant to blight is the safest way possible from both environmental and disease management perspective. Therefore, breeding techniques for resistant varieties were started from the 19th century and is continued till now. The level of resistance shown by various potato varieties has been studied by many researchers (Njualem., et al. 2001). Biotechnology has also tried to achieve the resistance to late blight. However, genetically modified plants can't be used in organic production (Shapiro., et al. 1998). With the introduction of new strain of pathogen, resistant varieties won't be that effective as single gene governs the resistance. Varieties with low resistance are of little advantage as they provide some protection in dry season. Cultivars having partial resistance coupled with low dose of fungicide, are capable of controlling blight. High resistant varieties can alone check the pathogen even in the wettest of seasons. Most of the varieties that mature early are vulnerable to blight. Some varieties provide significant foliage resistance while some have useful tuber-blight resistance. But an ideal variety should give significant resistance to both the tuber and foliage blight [5].

In tropical areas, resistant varieties are the key components in management of late blight (Shtienberg., et al. 1994). However, it is not wise to rely on varietal resistance only as weather conditions play important role in the spread of disease. No matter how resistant a variety is, if a new strain of fungus is introduced, the resistance will no longer be achieved. Therefore, resistant varieties along with dosages of fungicide, is practical in eliminating the huge loss that might be incurred otherwise. The application of fungicide is varied according to the varietal resistance. The lower the resistance, the higher the application of chemical spray and vice-versa.

\section{Chemical control}

Fungicides application have been the main approach used worldwide, against late blight (CIP 1989). Fungicides are primarily applied in order to prevent infection in healthy plants unlike herbicides and insecticides which kill weeds or insects. With the progression of time, fungicides do weather and breakdown. Therefore, they provide temporary protection. Also, the application should be scheduled at intervals to prevent new growth as disease progresses (Lyr 1995). There are two categories of fungicides against late blight viz. protectant or penetrant. Timely application of fungicides is able to slow down or check the new symptoms but they are not able to cure established blight symptoms [6]. For effective result, fungicide application should be done before development of disease or as soon as the first symptom appears. The damage which has already been caused can't be cured even after killing pathogen. Only uninfected growth can be protected with the use of fungicides. There are only few fungicides able to act against pathogens after a plant is infected (McGrath 2004). Generally, systemic and broadspectrum fungicides are applied against late blight. Oospore produced by fertilization of $\mathrm{A} 1$ and $\mathrm{A} 2$ mating types, is resistant to the 
systemic fungicide, Metalaxyl making it ineffective. Tuber infection can be reduced by foliar application of fungicides. When treated with Ridomil@3kg/ha in the plots of varieties Bedassa, Gabissa, Chiro, Harchassa and Zemen, 80, 76, 75.5, 69 and 68\%, reduction in severity was obtained as $80,76,75.5,69$ and $68 \%$ respectively [7].

Fungicide application increases the cost of production, adversely affects the environment we live in, still, it has benefits enough to attract farmers who are poor in resources. However, application of fungicide alone is not the ultimate solution to the late blight. Higher amount of fungicide increases the input cost but the harvest is not in accordance. The focus should be more on reaping advantage in the long run. Therefore, use of resistant varieties along with reduced dose of fungicide must be practised. When applying fungicide, the entire canopy coverage is essential. This, in turn, provides better protection against disease leading to reduced tuber blight infection.

\section{Integrated disease management (IDM)}

Combination of various approaches only can lead to the control of late blight in potato. IDM, thus is a holistic approach integrating cultural practices, host-plant resistance and chemical control. Integrated management must be adopted by all producers, including large and small-scale farmers for the effective control of late blight. Fungicides can be one of the tools, but not the entire approach in integrated management. The collective approach is necessary for the significant late blight control [8]. Successful blight control can be achieved through integration of cultural measures, resistant cultivars and timely application of fungicides [3]. When host resistance is obtained, the amount of chemical required is automatically reduced to maintain late blight below economic threshold level (Jones 1998). In tropical condition where abundance of inocula can be found, Integrated Management is the most effective approach (Olanya., et al. 2004). Integrated approach combines the three aspects with different perspectives which are not complete solely. To achieve the complete control, these three aspects must amalgamate. Removal of cull piles, storing at proper place with optimum temperature and moisture level, use of resistant cultivars and frequent application of fungicide as less as possible, when practised on right time, the late blight can be controlled. The integrated management lets one act and enhance its effect by the use of other. This approach of integration is pivotal in the management of late blight of potato [9-16].

\section{Conclusion}

Potato was, is and will always continue to be one of the most important vegetables in the world. It helps farmers in developing countries to meet their needs by providing sufficient income. However, the constraints in potato production, are making it difficult to both generate income and to meet the demand of this increasing population. The main problem in potato cultivation is the severe disease 'Late blight.' For efficient management, only one method will not be appropriate. Therefore, integration of cultural practices, use of resistant varieties and timely application of chemical sprays, is utmost as new strains are developing in a faster pace. The basic understanding of the disease, its symptoms and life cycle is crucial in adopting timely precautions which is required to control the infestation of Phytophthora infestans. Integrated Disease Management (IDM), is not an option but a necessity in present context if we really want to enhance the quality and quantity of potato production.

\section{Bibliography}

1. Anonymous. "The International Potato Center Annual Report". International Potato Center, Lima, Peru. 59. In: "Social Impact and Economic Importance of Late Blight". GILB and CIP 2004 (1997).

2. Fry WE., et al. "Five reasons to consider Phytophthora infestans a reemerging pathogen". Phytopathology 105 (2015): 966-981.

3. Agrios GN. "Plant Pathology". 5th Edition. Academic Press, London, New York (2005): 922.

4. ATTRA (Appropriate Technology Transfer to Rural Area). Organic Alternatives for Late Blight Control in Potatoes. National Sustainable Agriculture Information Service (2004).

5. Anonymous (2007)

6. Beckerman J. "Understanding fungicide mobility". Purdue Extension BP-70-W (2008)

7. Binyam Tsedaley., et al. "Efficacy of Reduced Dose of Fungicide Sprays in the Management of Late Blight (Phytophthora infestans) Disease Potato (Solanum tuberosum L.) Varieties Haramaya, Eastern Ethiopia”. Journal of Biology, Agriculture and Healthcare 4 (2014a): 46-52. 
8. Martin MD., et al. "Genomic characterization of a South American Phytophthora hybrid mandates reassessment of the geographic origins of Phytophthora infestans". Molecular Biology and Evolution 33 (2016): 478-491.

9. G Small., et al. "The 2009 Late Blight Pandemic in Eastern USAcauses and results". Plant Disease 96 (2013): 296-306.

10. Gallegly M and Galindo J. "Mating types and oospores of Phytophthora infestans in nature in Mexico". Phytopathology 48 (1958): 274.

11. Hu CH., et al. "Recent genotypes of Phytophthora infestans in eastern USA reveal clonal populations and reappearance of mefenoxam sensitivity". Plant Disease 96 (2012): 1323-1330.

12. Ristaino J. "Pioneering Women in Plant Pathology". American Phytopathological Society APS (2017).

13. Knowing Your Enemy-Blight.

14. Bekele Kassa and Hailu Beyene. "Efficacy and economics of fungicide spray in the control of late blight of potato in Ethiopia". Code Number: CS01054. African Crop Science Journal 9 (2001): 245-250.

15. Bekele Kassa and Yaynu Hiskias. "Tuber yield loss assessment of potato cultivars with different levels of resistance to late blight". In: "Proceedings of the 3rd Annual Conference, of Crop Protection Society of Ethiopia." (Eshetu Bekele, Abdurahman Abdulahi, Aynekulu Yemane. eds.), 18-19 May, CPSE, Addis Abeba, Ethiopia (1996): 149-152.

16. Bevacqua KJ. "Late Blight of Potato and Tomato". Yard and Garden. Mannesota University Extension Service (2000).

Volume 3 Issue 11 November 2019

(c) All rights are reserved by Radhika Dhakal Sedhai.

Citation: Radhika Dhakal Sedhai. "Late Blight of Potato". Acta Scientific Agriculture 3.11 (2019): 20-24. 